\title{
Three Mutations in the Stalk Region of Hemagglutinin Affect the pH of Fusion and Pathogenicity of H5N1 Influenza Virus
}

\author{
N. F. Lomakina ${ }^{a, b}$, *, G. K. Sadykova ${ }^{b}$, T. A. Timofeeva ${ }^{b}$, I. A. Rudneva ${ }^{b}$, E. Yu. Boravleva ${ }^{a}$, \\ P. A. Ivanov ${ }^{b, c}$, A. G. Prilipov ${ }^{b}$, and A. S. Gambaryan ${ }^{a}$ \\ ${ }^{a}$ Chumakov Federal Scientific Center for Research and Development of Immune-and-Biological Products, \\ Russian Academy of Sciences, Moscow, 108819 Russia \\ ${ }^{b}$ N.F. Gamaleya National Center of Epidemiology and Microbiology, Ministry of Health of the Russian Federation, \\ Moscow, 123098 Russia \\ ${ }^{c}$ The Mental Health Research Center, Moscow, 115522 Russia \\ *e-mail: nflomakina@yandex.ru \\ Received April 9, 2018; in final form, May 16, 2018
}

\begin{abstract}
Previously, an attenuated variant $\mathrm{Ku} /$ at was obtained from the highly pathogenic avian influenza virus $\mathrm{A} /$ chicken/Kurgan/3/2005 (H5N1) by a reverse selection method aimed at increasing the virus resistance to a proteolytic cleavage and acidic $\mathrm{pH}$ values. In the $\mathrm{Ku} / \mathrm{at}, 10$ mutations in proteins $\mathrm{PB} 2, \mathrm{~PB} 1$, HA, $\mathrm{NA}$, and NS1 occurred. In comparison with the parental strain, the $\mathrm{pH}$ of the conformational transition of the viral glycoprotein hemagglutinin (HA) and virulence for mice and chickens have decreased in an attenuated variant. The purpose of this work is to clarify the role of three mutations in the stalk region of HA: Asp54Asn in HA1 and Val48Ile and Lys131Thr in HA2 (H3 HA numbering). To attain these ends, analogous substitutions were introduced into HA with a deleted polybasic cleavage site (important for pathogenicity) of the recombinant A/Vietnam/1203/04-PR8/CDC-RG (H5N1) virus, and so we created the VN3x-PR variant. Viruses VN3x-PR and $\mathrm{Ku} /$ at with the same three mutations, but different proteolytic cleavage sites in $\mathrm{HA}$, as well as the corresponding initial viruses, were tested for pathogenicity in mice and in the erythrocyte hemolysis test. Compared with the parental strains, the virulence of their mutant variants in the case of intranasal infection of BALB/c mice decreased by $4-5$ orders of magnitude, and the $\mathrm{pH}$ of the conformational transition of HA decreased from 5.70-5.80 to 5.25-5.30, which is typical for low pathogenic natural isolates. Thus, as a result of the study, the attenuating role of these three mutations in HA has been proved, a correlation was established between the $\mathrm{pH}$ value of the HA conformational transition and the virulence of $\mathrm{H} 5 \mathrm{~N} 1$ influenza viruses, and it was shown that the polybasic cleavage site of the H5 HA does not always determine high pathogenicity of the virus.
\end{abstract}

Keywords: influenza A virus, H5N1, hemagglutinin, amino acid substitutions, reverse genetics, reverse selection, attenuation

DOI: $10.1134 / \mathrm{S} 0026893318060122$

\section{INTRODUCTION}

At the first stages of the reproduction cycle of the influenza virus, the viral protein, hemagglutinin (HA), interacts with receptors on the cell surface and mediates the fusion of viral and cell membranes to penetrate the virus into the cell. These two functions are carried out by different domains located in HA1 and HA2 chains of the HA molecule, respectively. In the native structure, HA is a trimer in which each monomer consists of HA1 and HA2 chains formed as a result of proteolytic cleavage of their common precursor and held by a disulfide bond. HA1 forms a globular part of the HA monomer protruding on the surface of a virion to which the stalk region adjoins with its opposite end immersed in the lipid envelope of a virion. HA2 is part of the stalk region of the HA molecule [1].
A viral particle bound to a receptor enters the endosome by endocytosis (Fig. 1a), within the endosome a gradual decrease in $\mathrm{pH}$ occurs via the operation of the ATP-dependent proton pump. In acidified environment of the endosome, the HA molecule undergoes a conformational change resembling a spring mechanism. The HA1 trimer chains dissociate and, as a result, the previously hidden part of the HA molecule is exposed. The HA2 area, folded in a native structure in the form of a long loop, unfolds and refolds into a superhelix in an acidified medium (Fig. 1b). The hydrophobic C-terminal part of the HA2 chain remains immersed in a lipid envelope of the virus, and the $\mathrm{N}$-terminal part of HA2, in which the short fusion peptide is located, becomes released and inserts into the cell membrane within the endosome, and thereby 


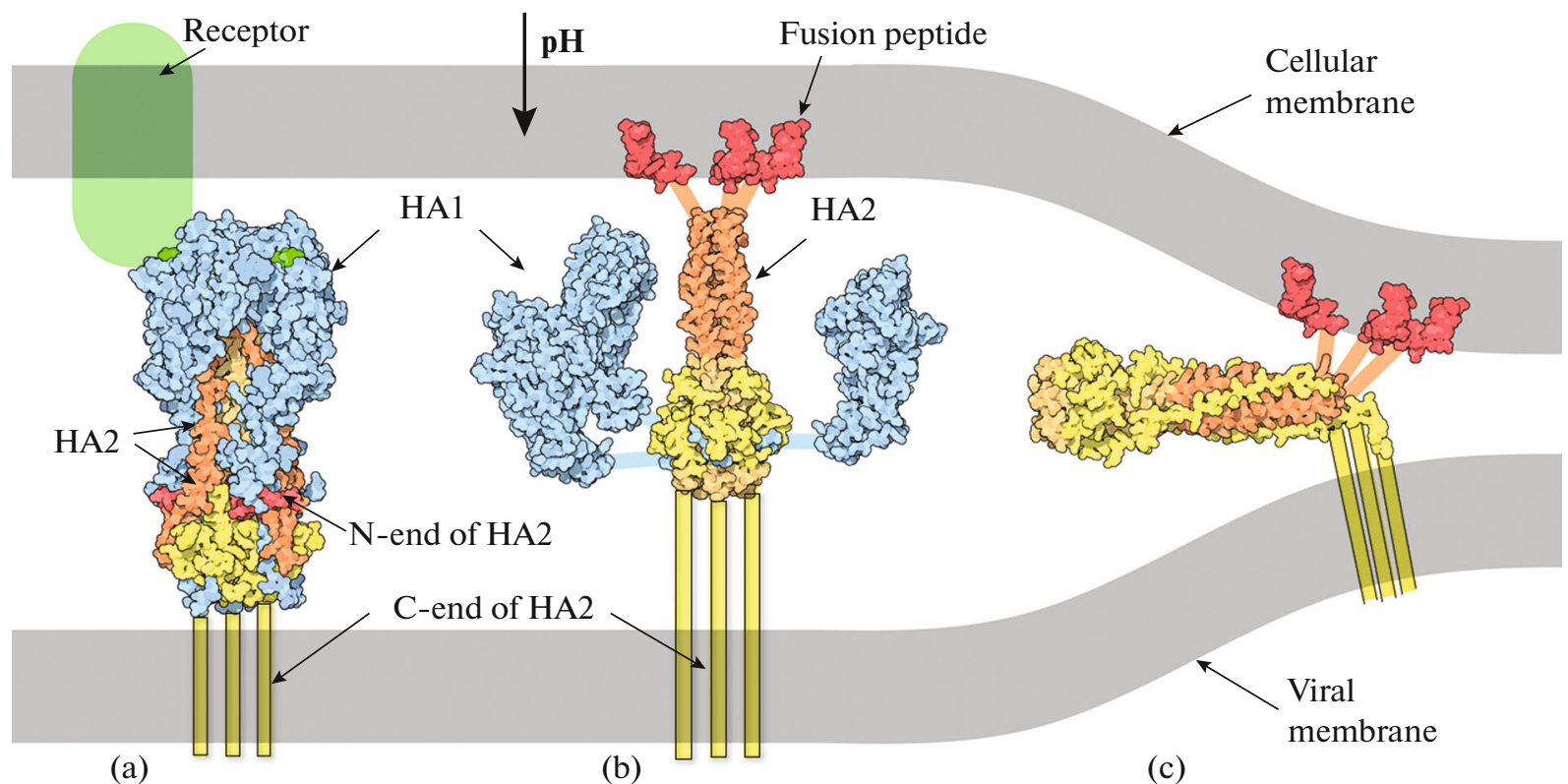

(a)

(b)

(c)

Fig. 1. Conformational change of an HA homotrimer in an endosome of the cell and fusion of membranes. (a) Interaction of HA1 with the cellular receptor. The C-terminal part of HA2 (depicted schematically) is immersed in the lipid envelope of the virus. (b) Decrease in $\mathrm{pH}$ leads to a change in HA conformation: the homotrimer unfolds and refolds taking another form. The fusion peptide at the N-terminus of the supercoiled part of HA2 is released and inserts into the endosomal membrane. (c) Altered structure of HA2 promotes approaching of the viral and endosomal membranes and their fusion. (Modified picture from the RCSB PDB database [1].)

facilitates the fusion of viral and cellular membranes (Fig. 1c). As a result, the viral genome enters the cytoplasm of the cell $[1,2]$. The fusion process is realized only if the HA precursor is cleaved by exogenous proteases on HA1 and HA2 chains. The structure of the cleavage site is considered one of determinants of the pathogenicity of influenza A viruses: if in avirulent viruses there is one amino acid residue of Arg, then, in highly virulent viruses, the pathogenicity determinant is represented by a sequence of several basic amino acid residues [3].

The $\mathrm{pH}$ value at which the HA conformational change and the membrane fusion occur is called $\mathrm{pH}$ of transition, or $\mathrm{pH}$ of the fusion, and is an important characteristic of the virus, that affects its stability, infectivity, replicative capacity, virulence, and adaptation to a new host $[4,5]$. This parameter is different for influenza viruses of different subtypes and different host species [6, 7].

Wild bird influenza viruses have a low transition $\mathrm{pH}$, from 4.9 to 5.4, and are resistant to low $\mathrm{pH}$ values, which is most likely related to the conditions of their life cycle. Wild duck influenza viruses are generally nonpathogenic for their natural host, in which they replicate in the lower intestine. They are characterized by an oral-fecal transmission route. With oral infection, entering the intestine to the replication site, the viruses need to overcome the acidic environment and action of stomach proteases $[8,9]$.
High virulent influenza viruses of the H5N1 subtype isolated from chickens and humans at the beginning of this century have a high $\mathrm{pH}$ transition value, $5.6-6.0$, and are unstable in a medium with $\mathrm{pH}$ below $5.6[6,7]$.

Between the transition $\mathrm{pH}$ and the virulence of $\mathrm{H} 5 \mathrm{~N} 1$ avian influenza viruses, a correlation is observed that is explained by it being easier for viruses with a high transition $\mathrm{pH}$ to enter the cell. They manage to leave an endosome at high $\mathrm{pH}$ and avoid falling into lysosomes with low $\mathrm{pH}$, where degradation of a foreign material occurs. Due to this, rapid replication and the formation of new virions occur in the cell, which are carried by blood throughout the body $[4,7,10]$.

An alternative mechanism to increase the virulence of influenza viruses with a high transition $\mathrm{pH}$ was suggested by Gerlach et al. [11]. They found a relationship between the membrane fusion $\mathrm{pH}$ and the ability of influenza viruses to replicate in cells activated by interferon. Among many genes and proteins regulated by interferons, there are transmembrane cellular proteins IFITM, which block the fusion of viral and cell membranes in the early stages of infection and thereby prevent the penetration of viruses into a cell and their replication. The authors showed that viruses with a high HA transition $\mathrm{pH}$ are less sensitive to interferon-activated IFITM proteins than viruses with a low transition $\mathrm{pH}$. This is one of the explanations for the high virulence of $\mathrm{H} 5 \mathrm{~N} 1$ viruses with high $\mathrm{HA}$ transition $\mathrm{pH}$ and low sensitivity to interferon and IFITM proteins [11]. 
Viral replication depends on both the properties of the virus and the properties of the host, more precisely on how well the virus adapts to the host cell factors which it uses during its reproduction. Sensitivity, or susceptibility, of cells to the influenza virus is determined, not only by receptors on its surface, but also by the $\mathrm{pH}$ in endosomes. Cells of different tissues and organism species differ in endosomal $\mathrm{pH}$. Moreover, in the same immortalized cell culture, the $\mathrm{pH}$ inside the endosomes can change with time as the early endosomes are converted to later ones and into lysosomes, as well as during differentiation and aging of the cells. For example, among the epithelial cells of human bronchioles, two types of cells were found that, with outward similarity, differed in susceptibility to infection with influenza viruses [7]. More sensitive cells had endosomes with low $\mathrm{pH}$, and cells with high endosomal $\mathrm{pH}$ were less sensitive to wild bird flu viruses, but had a high susceptibility to highly virulent strains of $\mathrm{H} 5 \mathrm{~N} 1$.

At the fusion of viral and cell membranes, a delicate balance must be maintained between the endosomal $\mathrm{pH}$ of a cell and the conformational stability of viral HA [7]. The conformational change of HA for each virus occurs at a certain characteristic for its medium $\mathrm{pH}$ value and this process is irreversible. If HA undergoes a conformational transition earlier than it enters a cell, then its inactivation occurs. As a result, the virus loses its ability to infect the cell. This explains low effectiveness of living vaccines based on H5 HA for mammals. A virus with a natural high $\mathrm{pH}$ transition loses infectivity in nasal passages where nasal mucosal secretions create an acidified environment [12].

When a virus with a low transition $\mathrm{pH}$ (like that of wild bird flu viruses) enters a cell with a high endosomal $\mathrm{pH}$, there is no change in the conformation of the $\mathrm{HA}$, the genetic material of the virus does not enter the cytoplasm, and, therefore, the virus does not replicate. Instead, it enters the lysosome, where it undergoes degradation.

The transition of the influenza virus to new host is also accompanied by a change in the $\mathrm{pH}$ of the HA transition, which can be considered an adaptation characteristic of the virus. Thus, the adaptation of wild waterfowl viruses to pigs was accompanied by the accumulation of mutations in HA2 that led to an increase in the $\mathrm{pH}$ of the HA transition and a decrease in the stability of the virus in an acidic environment [9]. On the contrary, when the pandemic strain of the $\mathrm{H} 1 \mathrm{~N} 1$ influenza virus passed from pigs to humans, HA evolved to a lower transition $\mathrm{pH}$ : from 5.5-6.0 in "swine" viruses and 5.5 in early "human" isolates of 2009 to 5.2-5.4 in later strains isolated from people [13].

Adaptation of highly virulent H5N1 influenza viruses to mammals is associated with a lowering of the transition $\mathrm{pH}$, as shown by the example of four variants of the virus A/chicken/Vietnam/C58/04 (H5N1) with the transition $\mathrm{pH}$ of $6.3,5.9,5.6$, and 5.4. The first ( $\mathrm{pH}$ 6.3) did not replicate at all in mice due to rapid inactivation in an acid medium; the second and third ( $\mathrm{pH} 5.9$ and 5.6) successfully replicated in tissue cultures and were pathogenic for mice and ducks; and the fourth ( $\mathrm{pH} \mathrm{5.4)} \mathrm{was} \mathrm{the} \mathrm{most} \mathrm{pathogenic} \mathrm{for} \mathrm{mice,}$ but apathogenic for ducks [14].

The study of the HA structure of viruses differing in transition $\mathrm{pH}$ allowed identification of amino acid residues in HA2 which can participate in changing the conformation of HA. An introduction of corresponding mutations into HA of moderately virulent virus A/chicken/Vietnam/C58/04 (H5N1) showed that some mutations (Asn114Lys in HA2) lead to an increase of the transition $\mathrm{pH}$ and enhance virulence, and others (Tyr23His and Lys58Ile in HA2) lead to a decrease of the transition $\mathrm{pH}$, an increase of the stability of the virus in acidic medium, and a decrease of virulence [4, 12, 15].

We investigated the mutations in HA that resulted from the selection of highly virulent virus A/chicken/ Kurgan/3/2005 (H5N1) on the grounds of acid resistance and attenuation for chicken embryos [16]. The introduction of similar mutations in HA of recombinant virus A/Vietnam/1203/04-PR8/CDC-RG (H5N1) made it possible to prove that the detected mutations contribute to a conformational change in $\mathrm{H} 5 \mathrm{HA}$ at lower $\mathrm{pH}$ and lead to attenuation of $\mathrm{H} 5 \mathrm{~N} 1$ viruses.

\section{EXPERIMENTAL}

Viruses. Recombinant influenza virus VN(H5N1)PR8/CDC-RG (VN-PR), which includes $H A$ and neuraminidase $(N A)$ genes of strain A/Vietnam/1203/2004 (H5N1) and genes of internal proteins of strain A/Puerto Rico/8/34 (H1N1), as well as a system of eight plasmids [17] containing DNA copies of all segments of this virus, were kindly provided by Dr. R. Webster (St. Jude Children's Research Hospital, Memphis, USA). Using the QuikChange XL SiteDirected Mutagenesis Kit (Stratagene, USA), three mutations were introduced into the $H A$ gene. Then we obtained mutant virus VN3x-PR (Fig. 2) containing substitutions Asp54Asn in HA1 and Val48Ile and Lys131Glu in HA2 (HA numbering according to $\mathrm{H} 3$ ) due to plasmid transfection into mixed culture HEK-293T-MDCK. Subsequently, the viruses were cultured in 10-day embryonated chicken eggs. Infectivity of the influenza virus was determined as a dose at which $50 \%$ of chicken embryos become infected $\left(\mathrm{EID}_{50}\right)$. The content of the influenza virus in the allantoic fluid of embryonated chicken eggs was determined in a hemagglutination assay with a $1 \%$ suspension of chicken red blood cells according to a generally accepted method [18].

Isolation of highly virulent influenza virus A/chicken/Kurgan/3/2005 (Ku/05) and its derivative variant A/chicken/Kurgan/3654at/2005 (Ku/at) attenuated by the reverse selection method have been described previously [16]. 


$\begin{array}{llllllll}10 & 20 & 30 & 40 & 50 & 60 & 70 & 80\end{array}$

VN-PR MEKIVLLFAIVSLVKSDQICIGYHANNSTEQVDTIMEKNVTVTHAQDILEKKHNGKLCDLDGVKPLILRDCSVAGWLLGN

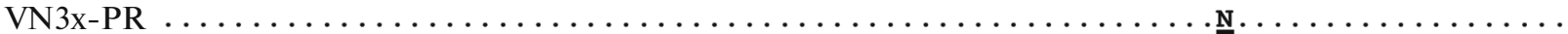

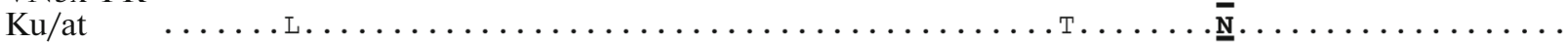

$\mathrm{Ku} / 05$

............

90

$110 \quad 120$

130

140

150

160

VN-PR PMCDEFINVPEWSYIVEKANPVNDLCYPGDFNDYEELKHLLSRINHFEKIQIIPKSSWSSHEASLGVSSVCPYQGKSSFF

VN3x-PR

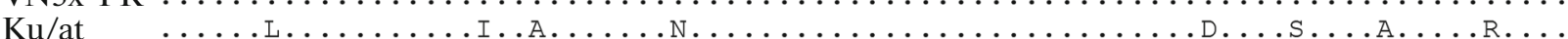

$\begin{array}{rrrrrrr}170 & 180 & 190 & 200 & 210 & 220 & 230\end{array}$

VN-PR RNVVWLIKKNSTYPTIKRSYNNTNQEDLLVLWGIHHPNDAAEQTKLYQNPTTYISVGTSTLNQRLVPRIATRSKVNGQSG

VN3X-PR

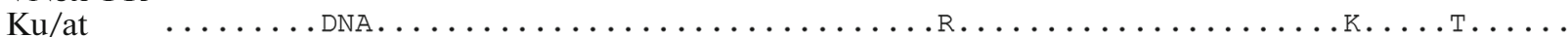

$\begin{array}{lllllll}250 & 260 & 270 & 280 & 290 & 300 & 310\end{array}$

VN-PR RMEFFWTILKPNDAINFESNGNFIAPEYAYKIVKKGDSTIMKSELEYGNCNTKCQTPMGAINSSMPFHNIHPLTIGECPK

VN3x-PR

$\mathrm{Ku} / \mathrm{at}$

$\mathrm{Ku} / 05$

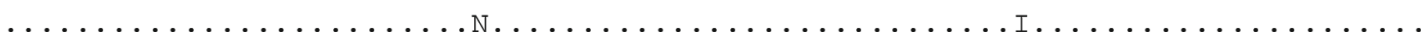

330

340

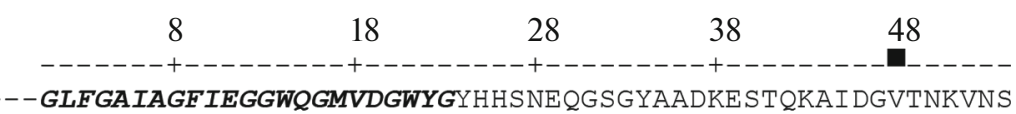

VN-PR YVKSNRLVLATGLRNSPQIETR----GLFGAIAGFIEGGWQGMVDGWYGYHHSNEQGSGYAADKESTQKAIDGVTNKVNS

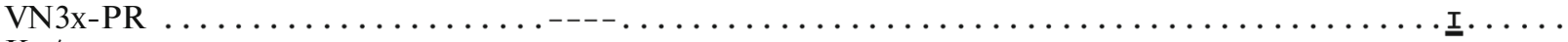

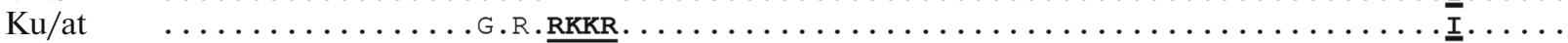

$\mathrm{Ku} / 05$

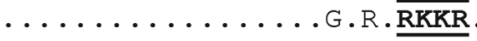

...........

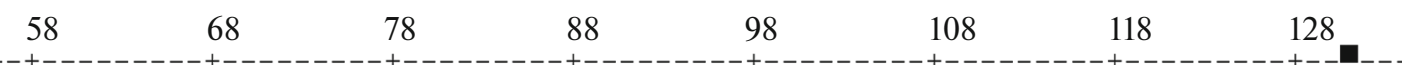

VN-PR IIDKMNTQFEAVGREFNNLERRIENLNKKMEDGFLDVWTYNAELLVLMENERTLDFHDSNVKNLYDKVRLQLRDNAKELG

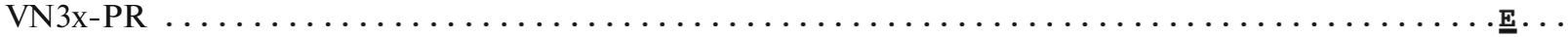

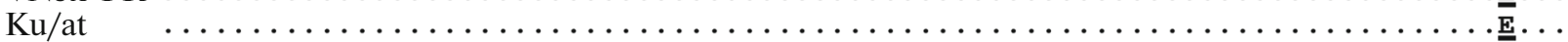

$\mathrm{Ku} / 05$

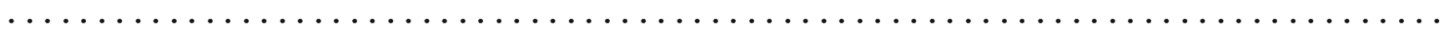
138
148
158
168
178
188
198
208

VN-PR NGCFEFYHKCDNECMESVRNGTYDYPQYSEEARLKREEISGVKLESIGIYQILSIYSTVASSLALAIMVAGLSLWMCSNG

VN3x-PR

$\mathrm{Ku} / \mathrm{at}$

$\mathrm{Ku} / 05$

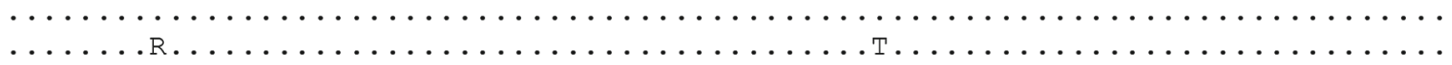

\begin{tabular}{|c|c|}
\hline & 218 \\
\hline VN-PR & SIOCRTCI \\
\hline VN3x-PR & 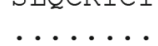 \\
\hline $\mathrm{Ku} / \mathrm{at}$ & . \\
\hline $\mathrm{Ku} / 05$ & 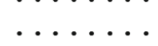 \\
\hline
\end{tabular}

Fig. 2. Amino acid sequences of HA of H5N1 influenza viruses: recombinant strain VN(H5N1)-PR8 (VN-PR) and its mutant VN3x-PR; strain A/chicken/Kurgan/3/2005 (Ku/05) and its attenuated variant A/chicken/Kurgan/3654at/2005 (Ku/at). Three identical amino acid substitutions in $\mathrm{VN} 3 \mathrm{x}-\mathrm{PR}$ and $\mathrm{Ku} / 05$ are marked with a black square; the polybasic cleavage site is underlined, the fusion peptide at the N-terminus of HA2 is italicized.

The nucleotide and amino acid sequences of these viruses are presented in the GenBank database (https://www.ncbi.nlm.nih.gov/nuccore) under the accession numbers DQ323672-DQ323679, HQ724520HQ724527, ABC48787, and ADU02098.
Sequencing. The structure of the viruses used in this work was controlled by sequencing the complete genome. Viral RNA was isolated using the QIAamp Viral RNA Mini Kit (Qiagen, Germany). After reverse transcription with the MMLV reverse transcriptase 
and subsequent polymerase chain reaction with universal primers $[19,20]$, amplified fragments were separated by agarose gel electrophoresis, extracted from gel using DNA Extraction Kit (D1031, Isogen Laboratory, Russia), and sequenced by the Sanger method using specific primers, the BigDye Terminator v3.1 Cycle Sequencing Kit (Applied Biosystems, United States) and an ABI Prism 3130XL device (Applied Biosystems).

Nucleotide and amino acid analysis. The DNASTAR Sequence Analysis Software Package (DNASTAR Inc.) was used to assemble sequence fragments, to align and analyze the sequences. Classification of genetic belonging of the viruses investigated was established based on the search for a near relation in the BLAST program (https://blast.ncbi.nlm.nih.gov/Blast.cgi) and in accordance with the WHO nomenclature [21]. Genetic and phenotypic characteristics of influenza viruses were obtained due to the Internet resource Influenza Research Database (IRD) (http://www.fludb.org) [22].

Mutations in a three-dimensional HA model based on the 2FK0 structure (https://www.rcsb.org/structure/2FK0) [23] were localized using RasWin 2.7.5 software (www.rasmol.org).

The determination of $\mathrm{pH}$ values of the $\mathrm{HA}$ conformational transition was performed using a hemolysis assay at different $\mathrm{pH}$ values as described earlier [12, 16].

Pathogenicity analysis of influenza viruses was performed on the BALB/c mice weighing 10-12 $\mathrm{g}$ with intranasal infection at doses of $10^{1}$ to $10^{5} \mathrm{EID}_{50}$ /mouse in a volume of $50 \mu \mathrm{L}$. Each dose of the virus was used to infect a group of five to six mice. The control group was injected with a diluted saline solution of allantoic fluid without the virus. The survival and weight of the mice were recorded within 12 days after infection. A lethal dose causing the death of half of the mice in the group $\left(\mathrm{LD}_{50}\right)$ was expressed in $\mathrm{EID}_{50}$.

\section{RESULTS OF THE STUDY}

\section{Locating and Characterization of Mutant Viruses}

Earlier we were able to attenuate the highly virulent $\mathrm{Ku} / 05$ influenza virus isolated from chickens, creating conditions simulating the life cycle of wild duck viruses. We called this approach "reverse selection", which was aimed at reducing the virulence for chicken embryos, increasing the resistance to proteolytic cleavage and acidic $\mathrm{pH}$ values. The attenuated $\mathrm{Ku} / \mathrm{at}$ variant, not pathogenic for mice and with weakened virulence for chickens, retained the polybasic cleavage site in HA and acquired 10 amino acid substitutions in the functionally important regions of the viral proteins HA, NA, PB1, PB2, NP, and NS1 [16].

Three substitutions in HA appeared to be reversions to the consensus amino acids of wild duck influenza viruses and are found in the stalk region of the HA trimmer: Asp54Asn in HA1 and Val48Ile and Lys131Glu in HA2 (Fig. 3).

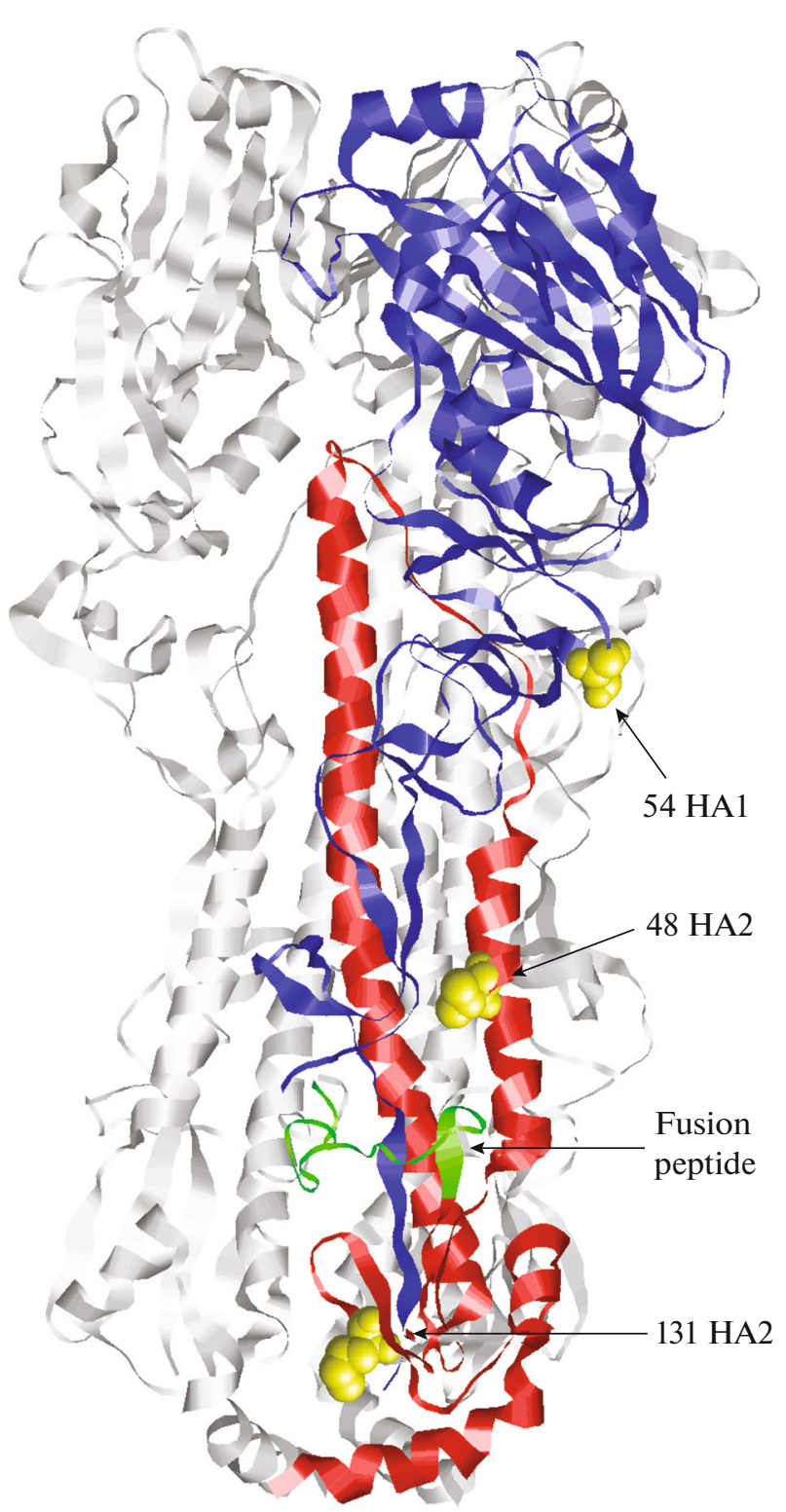

Fig. 3. Model of homotrimer HA of virus A/Vietnam/ $1203 / 2004$ (H5N1) based on the crystal structure of 2FK0 (doi 10.2210/pdb2FK0/pdb) [23]. Two monomers are colored pale gray. In the third monomer, subunits are highlighted by the color: HA1 (blue) and HA2 (red). Amino acid residues of Asp54 in HA1 and Val48 and Lys131 in HA2 are designated, which have been replaced in the recombinant $\mathrm{VN} 3 \mathrm{x}-\mathrm{PR}$ virus. The fusion peptide, located at the N-terminus of HA2, is highlighted in green.

To determine the functional role of substitutions that occurred in HA, we used the reverse genetics method. Into HA of the recombinant VN-PR virus, 3 point mutations have been introduced that are of interest to us. The resulting triple mutant VN3x-PR contained the $H A$ gene of virus A/Vietnam/1203/2004 (H5N1) with a deletion coding the polybasic proteolytic cleavage site. The primary structure of HA for 


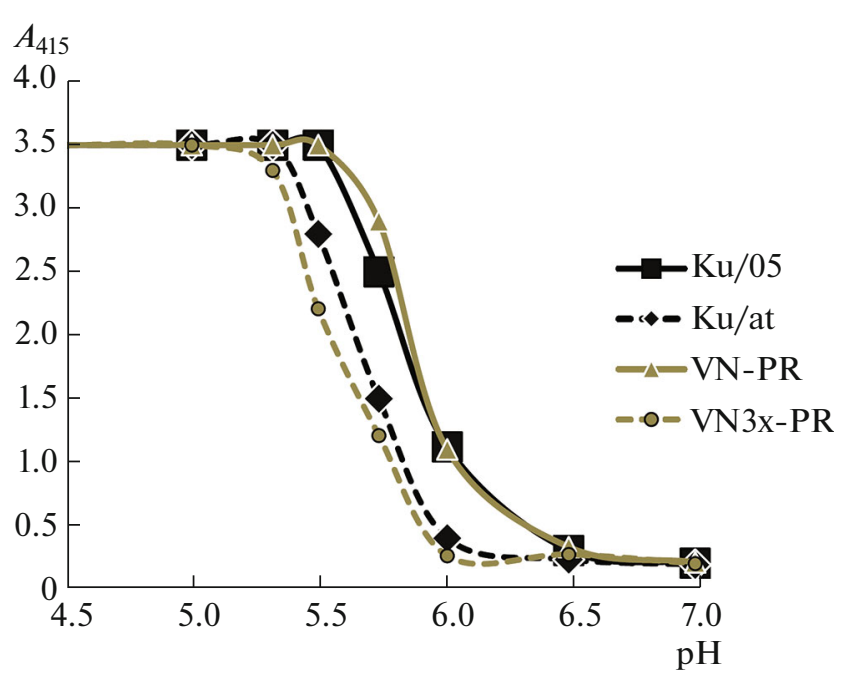

Fig. 4. The pH relationship of chicken erythrocyte hemolysis in the presence of influenza viruses VN(H5N1)-PR8 (VN-PR) and its mutant VN3x-PR, and also influenza virus $\mathrm{A} /$ chicken/Kurgan/3/2005 (Ku/05) and its attenuated variant $\mathrm{Ku} /$ at. At neutral $\mathrm{pH}$ values, influenza viruses do not induce hemolysis of erythrocytes, and at $\mathrm{pH}<5.3$ full hemolysis in all samples is observed.

initial and mutant viruses is shown in Fig. 2. At the amino acid level, the divergence between the original viruses $\mathrm{VN}-\mathrm{PR}$ and $\mathrm{Ku} / 05$ was $3.7 \%$, indicating that they belong to different clades ( 1 and 2.2, respectively) of the same genetic line of highly virulent $\mathrm{H} 5$ influenza viruses originating from $\mathrm{A} /$ goose/Guangdong/1/96 [21].

On a three-dimensional structure of the HA molecule (Fig. 3), amino acids at positions 54 in HA1 and 48 and 131 in HA2 are located in the stalk region where the remote amino acid residues of one chain or different chains and subunits of the homotrimer are in contact. Thus, Asp54 in HA1 is in close contact with Thr279 and Lys280 (HA1), Val48 (HA2) is in contact with Thr318 (HA1), and Lys131 (HA2) is in contact with Tyr141 and Arg127 (HA2) of the neighboring subunit [16]. Mutations in contact sites can change the mobility of a molecule and affect the parameters of the conformational transition of HA.

Table 1. Effect of point mutations in HA of influenza A viruses subtype $\mathrm{H} 5 \mathrm{~N} 1$ on $\mathrm{pH}$ of the conformational transition

\begin{tabular}{l|l|c}
\hline \multicolumn{1}{c|}{ Nature of HA } & \multicolumn{1}{c|}{ Virus } & $\begin{array}{c}\text { pH of conformational } \\
\text { transition* }\end{array}$ \\
\hline \multirow{2}{*}{ Initial } & $\mathrm{Ku} / 05$ & $5.70 \pm 0.05$ \\
\cline { 2 - 3 } & $\mathrm{VN}-\mathrm{PR}$ & $5.80 \pm 0.05$ \\
\hline $\begin{array}{l}\text { HA with 3 substitu- } \\
\text { tions }\end{array}$ & $\mathrm{Ku} / \mathrm{at}$ & $5.30 \pm 0.05$ \\
\cline { 2 - 3 } & $\mathrm{VN} 3 \mathrm{x}-\mathrm{PR}$ & $5.25 \pm 0.05$ \\
\hline
\end{tabular}

* The results are presented as mean \pm SD calculated based on three independent experiments.
Conformational Transition Parameters of HA

The $\mathrm{pH}$ value of the HA transition was determined in the erythrocyte hemolysis assay, which is based on the fact that HA of the influenza virus agglutinates erythrocytes at neutral $\mathrm{pH}$ values, while low $\mathrm{pH}$ results in their hemolysis. The degree of hemolysis, which can be measured by optical density at $415 \mathrm{~nm}$, depends on the conformational state of HA, which is determined by the $\mathrm{pH}$ of the medium $[12,16]$.

Figure 4 shows the hemolysis curves of chicken erythrocytes in the presence of influenza viruses under study at different $\mathrm{pH}$ values. The hemolysis curves of the original $\mathrm{Ku} / 05$ and $\mathrm{VN}-\mathrm{PR}$ viruses matched (Fig. 4, solid lines). In their presence, hemolysis of about $70 \%$ of erythrocytes is observed at $\mathrm{pH}$ 5.7-5.8. For mutant viruses $\mathrm{Ku} /$ at and VN3X-PR (Fig. 4, dotted lines), the same level of hemolysis is observed at $\mathrm{pH}$ values of $0.40-0.55$ units lower. Thus, the identical substitutions in three H5 HA positions of influenza viruses of different clades led to the same decrease in the transition $\mathrm{pH}$ (Table 1).

\section{Reproductive Properties of Viruses}

Viruses $\mathrm{Ku} / \mathrm{at}, \mathrm{VN}-\mathrm{PR}$, and $\mathrm{VN} 3 \mathrm{x}-\mathrm{PR}$ replicated well in chicken embryos up to a titer of 512 in the hemagglutination assay. The $\mathrm{Ku} / 05$ virus killed embryos in 24-36 hours, so the maximum titer of its accumulation did not exceed 64 . In the MDCK cell culture, the titers of VN-PR and VN3x-PR viruses reached 128 , while titers of $\mathrm{Ku} / 05$ and $\mathrm{Ku} /$ at did not exceed 8 and 16 , respectively.

\section{Virus pathogenicity for mice}

$\mathrm{The} \mathrm{Ku} / 05$ and $\mathrm{Ku} /$ at viruses differ in pathogenicity for mice (Table 2). The lethal dose of the original highly virulent strain $\mathrm{Ku} / 05$ is close to its infectious dose; while the intranasal infection with a dose of $10 \mathrm{EID}_{50}$ induces a death of all mice. In contrast, mice infected with a high dose $\left(10^{5} \mathrm{EID}_{50}\right)$ of $\mathrm{Ku} /$ at stayed alive and gained weight. In $\mathrm{Ku} / \mathrm{at}$, the decrease in virulence may be due to cumulative mutations in several viral proteins [16].

The pair of viruses VN-PR and VN3x-PR differ from each other only by three amino acid residues in HA. The recombinant VN-PR virus, intended for manufacturing an inactivated vaccine, proved to be pathogenic to mice, as well as highly virulent to $\mathrm{Ku} / 05$. Strain VN3x-PR with three substitutions in HA showed lower virulence compared to parent VN-PR. Mice infected with this virus started to lose weight two days later, and, at the doses of $\times 10^{2}, 10^{3}$, and $10^{4} \mathrm{EID}_{50}$, up to $70 \%$ of mice survived, while the survival rate of mice infected with the same doses of VN-PR was 10, 0 , and $0 \%$. Thus, the H5N1 influenza virus with HA substitutions, which lower the transition $\mathrm{pH}$ from 5.80 to 5.25 , became less virulent for mice. 
Table 2. Effect of point mutations in HA on the pathogenicity of influenza A viruses subtype H5N1 for mice

\begin{tabular}{l|l|c}
\hline \multicolumn{1}{c|}{ Nature of HA } & \multicolumn{1}{c|}{ Virus } & $\begin{array}{c}\text { Lethal dose, } \\
\log \left(\mathrm{EID}_{50}\right) \pm \mathrm{SD}^{*}\end{array}$ \\
\hline \multirow{2}{*}{ Initial } & $\mathrm{Ku} / 05$ & $<1$ \\
\cline { 2 - 3 } & $\mathrm{VN}-\mathrm{PR}$ & $1 \pm 0.3$ \\
\hline $\begin{array}{l}\text { HA with 3 substitu- } \\
\text { tions }\end{array}$ & $\mathrm{Ku} / \mathrm{at}$ & $>5$ \\
\cline { 2 - 3 } & $\mathrm{VN} 3 \mathrm{x}-\mathrm{PR}$ & $5 \pm 0.5$ \\
\hline
\end{tabular}

* Results based on three independent experiments are presented as an averaged decimal $\log$ of a dose of the virus expressed in EID $_{50}$ leading to the death of $50 \%$ of mice \pm standard deviation.

\section{DISCUSSION OF THE RESULTS}

In this work we examined the HA of highly virulent influenza viruses $\mathrm{H} 5 \mathrm{~N} 1$ that belong to different clades of the same genetic line (A/goose/Guangdong/1/96) and differ in the hosts species from which they were isolated. Virus $\mathrm{Ku} / 05$ (clade 2.2) has been isolated from chickens and its attenuated variant $\mathrm{Ku} /$ at has been obtained on chicken embryos, thus these viruses have an "avian" origin. The $H A$ and $N A$ genes of recombinant VN-PR belong to a human-isolated avian-borne virus A/Vietnam/1203/2004 (H5N1, clade 1) and are built into the context of the genome of the human influenza virus A/Puerto Rico/8/34 (H1N1).

In experiments on mice, a high degree of attenuation of $\mathrm{Ku} /$ at was observed, despite the presence of a polybasic cleavage site in its HA. Even at the highest dose of infection $10^{5} \mathrm{EID}_{50}$ mice remained alive. Earlier in experiments on chickens, we showed that the pathogenicity index ${ }^{1}$ of $\mathrm{Ku} /$ at is zero, and, for the original virus $\mathrm{Ku} / 05$, it is 2.9 [24].

Despite the fact that the polybasic cleavage site was removed from $\mathrm{HA}$, the recombinant $\mathrm{VN}-\mathrm{PR}$ virus was pathogenic for mice. According to IRD data [22], the genes derived from the A/Puerto Rico/8/34 virus contain pathogenicity determinants in the proteins $\mathrm{PB} 2$ (Lys627), M1 (Asp30 and Ala215), and NS1 (Ser42). It is possible that some of them or a combination of them provide high virulence of the VN-PR virus.

The HA amino acid sequences of viruses $\mathrm{Ku} / 05$ and $\mathrm{Ku} /$ at differ from VN-PR and VN3x-PR by the primary structure of the proteolytic cleavage site. In $\mathrm{HA}$ of viruses $\mathrm{Ku} / 05$ and $\mathrm{Ku} / \mathrm{at}$, this is a sequence of several basic amino acid residues, which is considered one of the markers of high pathogenicity of influenza A viruses, while, in HA of VN-PR and VN3x-PR, there is only one Arg residue in the cleavage site (Fig. 2). Despite such significant differences in $\mathrm{Ku} / 05$ and

\footnotetext{
${ }^{1}$ The pathogenicity index is determined by the physical state and survival of 6-week-old chicks after intravenous infection with tenfold dilutions of the virus. For low-virulent viruses, its value is in a range from 0 to 1.2 ; for highly virulent it is greater than 1.2 (the maximum value is 3 ) [18].
}

VN-PR viruses, three identical mutations introduced into their HA resulted in similar effects: lower $\mathrm{pH}$ values of the HA conformational transition and reduced virulence for mice.

Summarizing, we can draw the following conclusions: (1) Mutations of Asp54Asn in subunits HA1 and Val48Ile and Lys 131Thr mutations in the subunit HA2 lead to a decrease in $\mathrm{pH}$ of HA conformational transition of by $0.40-0.55$ units $(\mathrm{pH} 5.25-5.30$ as against $5.70-5.80)$ and a significant decrease in virulence of viruses in mice compared to parental viruses. (2) The HA polybasic cleavage site, which is considered one of the main factors of the pathogenicity of $\mathrm{H} 5$ influenza viruses, does not always provide a phenotypic manifestation of high virulence. Pathogenicity, apparently, is of polygenic nature and depends on both the structure of HA and other viral proteins, and also species belonging of an infected organism.

Point mutations in HA2 chain that cause a change in $\mathrm{pH}$ of the HA transition and the virulence of the influenza virus had been investigated by many scientists [4, 12, 15], but mutations of Asp54Asn in HA1, and Val48Ile and Lys131Thr in HA2 have been detected and studied for the first time.

\section{ACKNOWLEDGMENTS}

The authors are grateful to B.I. Timofeev, a senior researcher at the N.F. Gamaleya National Center of Epidemiology and Microbiology, for help in analyzing the 3D-model of HA and preparing illustrations.

The work was supported by the Russian Foundation for Basic Research (project no. 17-04-00148 A).

\section{COMPLIANCE WITH ETHICAL STANDARDS}

The authors declare that they have no conflict of interest. This article does not contain any studies involving animals or human participants performed by any of the authors.

\section{REFERENCES}

1. Goodsell, D.S. 2006. Molecule of the month: Hemagglutinin. RCSB PDB Molecule of the month. http:// pdb101.rcsb.org/motm/76. doi 10.2210/rcsb_pdb/ mom_2006_410.2210/rcsb_pdb/mom_2006_4

2. Hamilton B.S., Whittaker G.R., Daniel S. 2012. Influenza virus-mediated membrane fusion: Determinants of hemagglutinin fusogenic activity and experimental approaches for assessing virus fusion. Viruses. 4 (7), 1144-1168. doi 10.3390/v4071144

3. Influenza A cleavage sites. 2016. Version 6. http://www. offlu.net/fileadmin/home/en/resource-centre/pdf/ Influenza_A_Cleavage_Sites.pdf.

4. Reed M.L., Bridges O.A., Seiler P., Kim J.-K., Yen H.-L., Salomon R., Govorkova E.A., Webster R.G., Russell C.J. 2010. The $\mathrm{pH}$ of activation of the hemagglutinin protein regulates $\mathrm{H} 5 \mathrm{~N} 1$ influenza virus pathogenicity and transmissibility in ducks. J. Virol. 84, 1527-1535. 
5. Hanson A., Imai M., Hatta M., McBride R., Imai H., Taft A., Zhong G., Watanabe T., Suzuki Y., Neumann G., Paulson J.C., Kawaoka Y. 2015. Identification of stabilizing mutations in an $\mathrm{H} 5$ hemagglutinin influenza virus protein. J. Virol. 90 (6), 2981-2992. doi 10.1128/JVI.02790-15

6. Galloway S.E., Reed M.L., Russell C.J., Steinhauer D.A. 2013. Influenza HA subtypes demonstrate divergent phenotypes for cleavage activation and $\mathrm{pH}$ of fusion: implications for host range and adaptation. PLoS Pathog. 9, e 1003151.

7. Daidoji T., Watanabe Y., Ibrahim M.S., Yasugi M., Maruyama H., Masuda T., Arai F., Ohba T., Honda A., Ikuta K., Nakaya T. 2015. Avian influenza virus infection of immortalized human respiratory epithelial cells depends upon a delicate balance between hemagglutinin acid stability and endosomal pH. J. Biol. Chem. 290 (17), 10627-10642. doi 10.1074/jbc.M114.611327

8. Webster R.G. 1997. Influenza virus: Transmission between species and relevance to emergence of the next human pandemic. Arch. Virol. Suppl. 13, 105-113.

9. Baumann J., Kouassi N.M, Foni E., Klenk H.D., Matrosovich M. 2015. H1N1 swine influenza viruses differ from avian precursors by a higher $\mathrm{pH}$ optimum of membrane fusion. J. Virol. 90 (3), 1569-1577. doi 10.1128/JVI.02332-15

10. DuBois R.M., Zaraket H., Reddivari M., Heath R.J., White S.W., Russell, C.J. 2011. Acid stability of the hemagglutinin protein regulates $\mathrm{H} 5 \mathrm{~N} 1$ influenza virus pathogenicity. PLoS Pathog. 7, e1002398

11. Gerlach T., Hensen L., Matrosovich T., Bergmann J., Winkler M., Peteranderl C., Klenk H.D., Weber F., Herold S., Pöhlmann S., Matrosovich M. 2017. pH optimum of hemagglutinin-mediated membrane fusion determines sensitivity of influenza A viruses to the interferon-induced antiviral state and IFITMs. J. Virol. 91 (11), e00246-17. doi 10.1128/JVI.00246-17

12. Krenn B.M., Egorov A., Romanovskaya-Romanko E., Wolschek M., Nakowitsch S., Ruthsatz T., Kiefmann B., Morokutti A., Humer J., Geiler J., Cinatl J., Michaelis M., Wressnigg N., Sturlan S., Ferko B., et al. 2011. Single HA2 mutation increases the infectivity and immunogenicity of a live attenuated $\mathrm{H} 5 \mathrm{~N} 1$ intranasal influenza vaccine candidate lacking NS1. PLoS One. 6 (4), e18577.

13. Russier M., Yang G., Rehg J.E., Wong S.S., Mostafa H.H., Fabrizio T.P., Barman S., Krauss S., Webster R.G., Webby R.J., Russell C J. 2016. Molecular requirements for a pandemic influenza virus: an acid-stable hemagglutinin protein. Proc. Natl. Acad. Sci. U. S. A. 113 (6), 1636-1641, doi 10.1073/pnas.1524384113

14. Zaraket H., Bridges O.A., Russell C.J. 2013. The pH of activation of the hemagglutinin protein regulates $\mathrm{H} 5 \mathrm{~N} 1$ influenza virus replication and pathogenesis in mice. J. Virol. 87 (9), 4826-4834. doi 10.1128/JVI.03110-12

15. Reed M.L., Yen H.L., DuBois R.M., Bridges O.A., Salomon R., Webster R.G., Russell C.J. 2009. Amino acid residues in the fusion peptide pocket regulate the
$\mathrm{pH}$ of activation of the $\mathrm{H} 5 \mathrm{~N} 1$ influenza virus hemagglutinin protein. J. Virol. 83 (8), 3568-3580. doi 10.1128/JVI.02238-08

16. Lomakina N.F., Boravleva E.Yu., Kropotkina E.A., Yamnikova S.S., Drygin V.V., Gambaryan A.S. 2011. Attenuation of A/Chicken/Kurgan/3/2005 (H5N1) influenza virus using selection in an environment simulating the life cycle of wild duck viruses. Mol. Genet. Microbiol. Virol. 26 (3), 132-136.

17. Hoffmann E., Neumann G., Kawaoka Y., Hobom G., Webster R.G. 2000. A DNA transfection system for generation of influenza A virus from eight plasmids. Proc. Natl. Acad. Sci. U. S. A. 97, 6108-6113.

18. World Organization for Animal Health. 2018. Manual of Diagnostic Tests and Vaccines for Terrestrial Animals. http://www.oie.int/standard-setting/terrestrialmanual/access-online/

19. Stech J., Stech O., Herwig A., Altmeppen H., Hundt J., Gohrbandt S., Kreibich A., Weber S., Klenk H.D., Mettenleiter T.C. 2008. Rapid and reliable universal cloning of influenza A virus genes by target-primed plasmid amplification. Nucleic Acids Res. 36 (21), e139. doi 10.1093/nar/gkn646

20. Kreibich A., Stech J., Mettenleiter T.C., Stech O. 2009. Simultaneous one-tube full-length amplification of the NA, NP, M, and NS genes of influenza A viruses for reverse genetics. J. Virol. Methods. 159 (2), 308-310. doi 10.1016/j.jviromet.2009.04.020

21. World Health Organization/World Organisation for Animal Health/Food and Agriculture Organization (WHO/OIE/FAO). H5N1 Evolution Working Group. 2014. Revised and updated nomenclature for highly pathogenic avian influenza A (H5N1) viruses. Influenza Other Respir. Viruses. 8 (3), 384-388.

22. Squires R.B., Noronha J., Hunt V., García-Sastre A., Macken C., Baumgarth N., Suarez D., Pickett B.E., Zhang Y., Larsen C.N., Ramsey A., Zhou L., Zaremba S., Kumar S., Deitrich J., et al. 2012. Influenza research database: An integrated bioinformatics resource for influenza research and surveillance. Influenza Other Respir. Viruses. 6, 404-416. doi 10.1111/j.1750-2659.2011.00331.x

23. Stevens J., Blixt O., Tumpey T.M., Taubenberger J.K., Paulson J.C., Wilson I.A. 2006. Structure and receptor specificity of the hemagglutinin from an H5N1 influenza virus. Science. 312, 404-410. doi 10.1126/science. 1124513

24. Gambaryan A.S., Boravleva E.Y., Lomakina N.F., Kropotkina E.A., Gordeychuk I.V., Chvala I.A., Drygin V.V., Klenk H.D., Matrosovich M.N. 2016. Immunization with live nonpathogenic H5N3 duck influenza virus protects chickens against highly pathogenic H5N1 virus. Acta Virol. 60 (3), 316-327. doi 10.4149/ av_2016_03_316

Translated by A. Ostyak 